\title{
FORMA Y FUNCIÓN EN CASOS CLÍNICOS: Un Reto de la Práctica Basada en Evidencia
}

\author{
Diana Grandi ${ }^{12}$
}

Los logopedas especializados en M.O., según el área específica de nuestro ejercicio profesional, nos relacionamos de manera habitual con diferentes profesionales sanitarios. En esta presentación se hablará específicamente de la relación entre Ortodoncia y Logopedia. Se mostrarán casos clínicos en los que se observará el estado inicial y final después del tratamiento conjunto, analizándose los aspectos que se encuadran dentro de la práctica basada en la evidencia y aquellos que, en cambio, se evidencian como un desafío aún por conseguir.

Sabemos que el diagnóstico preciso es imprescindible para conseguir resultados exitosos, no sólo en nuestro tratamiento, sino también para contribuir al éxito del tratamiento de ortodoncia. Para ello necesitamos conocer y dominar las técnicas y recursos de evaluación y diagnóstico en M.O., así como los recursos específicos para tratar las diferentes alteraciones, según la maloclusión y el biotipo facial del paciente. Se requiere evidenciar no sólo los resultados de la evaluación, sino también los cambios que se producen a lo largo del tratamiento.

Forma y Función, dos caras de la misma moneda, que se interrelacionan y se influyen mutuamente, y por lo tanto requieren un trabajo interdisciplinario desde la misma evaluación. Trabajar sobre la forma sin atender a la función puede llevar al ortodoncista y al paciente al punto de partida, provocando una recidiva. Trabajar sobre la función sin equilibrar la forma, dificulta al logopeda y al paciente la consecución de los objetivos, ya que generalmente se produce una compensación en la función, pero no se consigue un nuevo patrón funcional. En cambio, el trabajo conjunto promueve, en muchos casos, el éxito del tratamiento y facilita además la estabilidad de los resultados...Pero ¿es la práctica basada en la evidencia el sustento de esa interrelación profesional?

Ese interrogante y algunos más que se desprenden del trabajo conjunto ortodoncia-logopedia, serán abordados en esta ponencia.

\section{REFERENCIAS BIBLIOGRÁFICAS}

1. GRANDI, D. "La utilización de recursos en el tratamiento logopédico miofuncional de las disfunciones orofaciales". Revista digital "Ortodoncia Clínica" Ed. Nexus,Médica, 2011; 14(1): 6-16.

2. MARCHESAN, I.Q. "Protocolo de Evaluación de Motricidad Orofacial", En: SUSANIBAR, F.; MARCHESAN, I.; PARRA, D y DIOSES, A. "Tratado de Evaluación de Motricidad Orofacial y áreas afines". Editorial EOS, Madrid, 2014.

12. Licenciada en Fonoaudiología. Máster en Bioética y Derecho. Logopeda especializada en Motricidad Orofacial. Actividad en consulta privada y en Clínica Marcó de Ortodoncia Lingual (Barcelona). Coordinadora del Máster de Motricidad Orofacial (FUB- EPAP) y de cursos de especialización en el área. Autora de artículos y capítulos de libros sobre la especialidad. Co-autora de Protocolos de Exploración Interdisciplinaria Orofacial y Protocolo para pacientes con síntomas de disfunción cráneo mandibular.

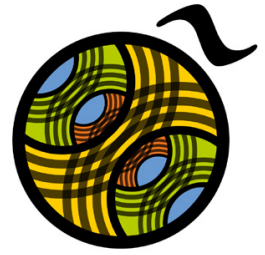


3. PUIGDOLLERS PÉREZ, A. La estabilidad de los tratamientos en mordidas abiertas. Comentarios sobre la investigación en ortodoncia". Rev. Esp. Ortod. 2012; 42:3-4

4. SUSANIBAR, F.; DIOSES, A.; CASTILLO, J. "Evaluación de Motricidad Orofacial" , En: SUSANIBAR, F.; MARCHESAN, I.; PARRA, D y DIOSES, A. "Tratado de Evaluación de Motricidad Orofacial y áreas afines". Editorial EOS, Madrid, 2014.

5. USTRELL, J. "Matriz funcional y clasificación de sus alteraciones", En DURÁN VON ARX et al. "Estímuloterapia en Ortodoncia. Control etiopatogénico de la recidiva". Editorial Médica Ripano, Madrid 2010. 